\title{
A GUERRA COMO PROBLEMA PARA OS ESTUDOS LITERÁRIOS
}

\author{
Jaime Ginzburg*
}

\begin{abstract}
Aesthetics and Ethics, empathy might be a very important concept. In this essay, we consider how war and literature can be related, in Literary Studies. War is not only a theme, but also a formal issue. Literary genres, realism and images of death are examined as relevant aspects in this matter. According to Frankfurt School, we comment texts written by Guimarães Rosa and Sérgio Chejfec, explaining how they confront images of war coming from the tradition of classical epic and conventional realism.
\end{abstract}

\section{KEY-WORDS: war, literature, empathy, Frankfurt School}

\author{
Veio uma palavra, veio, \\ veio pela noite, \\ queria brilhar, queria brilhar \\ Cinzas \\ Cinzas, cinzas \\ (Paul Celan)
}

Este texto é escrito em perspectiva pacifista, e por essa razão cada palavra dentro dele defende que a guerra exige uma reflexão crítica. A guerra tem seus defensores, inclusive no campo literário.

Um escritor canônico, reconhecido e amplamente estudado, José de Alencar, faz parte, há muito tempo, das recomendações de leitura de cursos universitários e da educação escolar. Seu valor artístico, reforçado por diversos manuais de história literária, parece estar acima de qualquer questionamento. No entanto, não está. No momento presente, os critérios de valor estético estão em debate, dentro do campo de pesquisas dedicado aos estudos de formação do cânone.

Alencar elogiou a guerra por escrito. Não me refiro aqui à legitimação de violência em sua ficção, assunto que exige ampla discussão. Especificamente lembro da Sexta Carta incluída na edição Cartas a favor da escravidão, publicada em 2008. Para uma perspectiva pacifista, esse texto é constrangedor, caracterizando a paz como "vergonha" e "vilania", em favor da soberania nacional (ALENCAR, 2008, p. 133). Os valores estéticos, necessariamente, devem estar articulados com valores éticos. Obras de

\footnotetext{
* Professor da Universidade de São Paulo (USP).
} 
um escritor que defende a violência, quando lidas sem a devida perspectiva crítica, podem ser consideradas símbolos altos de uma concepção de identidade nacional. Lendo Alencar, não surpreende que no Brasil a violência de Estado tenha sido tão defendida e continuada.

A guerra não é, para os estudos literários, apenas um tema. A partir da Escola de Frankfurt, o debate inclui a proposição de que exista uma conexão entre tema e forma. Isto é, há condicionamentos formais articulados com as concepções de guerra. As heranças hegelianas de abordagem da épica tradicional estão associadas à legitimação da violência. O problema do conceito de representação, que vem sendo examinado com atenção para suas variações históricas e de suas limitações, é hoje estudado em suas relações com o conceito de catástrofe histórica.

As aproximações entre estética e ética levam a considerar a empatia como uma categoria fundamental para a interpretação de textos. Não se trata apenas de considerar a empatia do escritor com relação ao outro. Sobre esse assunto, cabe lembrar o espantoso ensaio de Anatol Rosenfeld sobre arte e fascismo, em que ele se pergunta em que medida a consciência de que um escritor é fascista condiciona a valorização de suas obras artísticas. $\mathrm{Na}$ década de 40 , em que foi redigido o ensaio, de fato, para um intelectual contrário à guerra, havia dificuldade de entender o papel a ser assumido pelos artistas. Séculos de tradição intelectual deveriam constituir estofo suficiente para evitar os massacres e genocídios. Não foi o que ocorreu. Então, por que nos damos ao trabalho de realizar produção de conhecimento? Para continuar fomentando a destruição e a desumanização?

$\mathrm{Na}$ contemporaneidade, o problema da empatia é examinado com muita complexidade. O pensamento de Wittgenstein, nesse sentido, foi muito importante, por elaborar de modo corajoso relações entre linguagem e dor. Suas ideias ajudam a ponderar, em análises textuais, a respeito da significação da dor do outro. Trata-se de pensar a empatia também no interior das obras. As construções de sujeitos líricos, narradores e personagens estão no horizonte desta abordagem. Além disso, as escolhas de adotar um modelo de um certo gênero literário, ou romper com ele, é também relevante. Mais ainda, interessa caracterizar a construção textual, como pautada por uma estética voltada para o efeito realista, ou para a ruptura com ela. Para trabalhar com a empatia em estudos literários, é necessário levar em conta três elementos. O primeiro consiste na configuração da morte. Existem textos sobre guerra em que a morte de inimigos é configurada como êxito, e portanto, como glória e alegria. Em outros, a morte de um indivíduo é observada a partir do olhar da perda, ou do inconformismo com a destruição. Quanto vale uma vida humana singular? Sua vida merece ser contada?

O segundo é a constituição do sujeito. Podemos encontrar textos pautados por imagens do sujeito caracterizadas pela capacidade de dominar a si mesmo, pelo controle da realidade externa. Na perspectiva traumática, diferentemente, o sujeito não dá conta de suas demandas, em conflito com sua própria memória, sendo incapaz de atribuir sentido completo à sua existência. Entre a totalidade e a fragmentação, cabe a pergunta: o que pode ou deve fazer um ser humano em uma guerra? Simone Weil leu, por exemplo, a Ilíada de Homero, sem reforçar as leituras canônicas, e contextualizando a obra a partir de um lugar de enunciação situado no século XX. Weil conseguiu apontar para o que há de terrível no interior da épica.

O terceiro é mais geral e diz respeito ao papel da palavra. Se a estética e a ética se articulam, esse problema se torna nuclear. Com Paul Celan, a relação entre a guerra e 
a palavra foi marcada pela negatividade. A destruição da guerra exigiria a reinvenção da língua, para que as condições de pensamento que levaram à catástrofe não se reproduzam. Esse é um dos fatores pelos quais Theodor Adorno valorizou muito o trabalho de Celan. Após a catástrofe, reinventar as palavras, para ter como dizer o que é necessário dizer. Theodor Adorno elaborou um problema, em coerência com outras ideias da Escola de Frankfurt, que se tornou importante para os estudos literários contemporâneos. Ele propõe que há uma relação entre o impacto da catástrofe e a ruptura com o realismo oitocentista. Cabe relacionar este problema com a crítica da guerra, e defender a expectativa de articulação entre Estética, Ética e Política.

Grande parte de nossa tradição de pensamento é baseada em René Descartes. Constantemente estamos preocupados em propor reflexões caracterizadas por coerência, nas quais esteja ausente a contradição. Este fundamento da racionalidade cartesiana beneficiou o movimento iluminista. Ele impregnou as tradições que sustentam o que hoje muitos consideram validade científica, em especial nas chamadas ciências duras. $\mathrm{O}$ Discurso do método de Descartes apresentava critérios capazes de evitar a formulação de ideias equivocadas. A busca da verdade era considerada prioritária. Entre esses critérios, estavam: não propor nenhuma ideia de maneira precipitada; ordenar os pensamentos, do mais simples ao mais complexo; dividir os problemas em partes e etapas; revisar o trabalho feito, evitando equívocos (DESCARTES, 1973, p. 45-46). Somos herdeiros de uma atitude de pensamento em que a busca de uma coerência é uma condição para o pensamento considerado legítimo. Sendo assim, é estabelecido um critério distintivo de valor, que diferencia ideias corretas e incorretas, oportunas e inoportunas.

Há algumas décadas, Theodor Adorno e Max Horkheimer escreveram a Dialética do esclarecimento, livro voltado para uma reflexão crítica sobre os empregos tradicionais do conceito de razão. O pensamento ordenado pode ser utilizado para diversos fins. A ciência pode ser empregada em favor de objetivos destrutivos. Habermas, em Conhecimento $e$ interesse, discute a mistificação da neutralidade científica. Para ele, não há pesquisa em que o valor seja definido pela coerência racional em si mesma: "a mediação entre sujeito e objeto [...] constitui-se inicialmente por ação e obra do interesse. [...] a força do interesse penetra no núcleo lógico da pesquisa" (HABERMAS, 1983, p. 308). Os interesses de um pesquisador estão diretamente ligados a suas concepções de conhecimento e ciência. No século XX, considerando as duas grandes guerras e o percurso da guerra fria, é possível verificar o andamento de um processo, que consiste em um investimento sistemático na ciência com fins militares, para configuração de armamentos com alto poder de destruição. É possível mapear uma extensa história de acúmulo e debate de conhecimentos eruditos em química, matemática, biologia e outras áreas, organizados em favor de planejamentos, financiados por governos, voltados para o aperfeiçoamento estrutural de recursos para a guerra. Francisco Foot Hardman, em ensaio sobre os recentes acontecimentos de horror no Japão, caracterizou os recursos nucleares desse país como "alta tecnologia da morte" (HARDMAN, 2011, p. 8).

A bomba lançada em Hiroshima e a câmara de gás utilizada em um campo de concentração no nazismo são evidências de que um elevado nível de conhecimento acadêmico, já na década de 1940, foi colocado à disposição do militarismo e da política, com a finalidade de realizar processos de extermínio. O contato entre a destruição em massa e a produção intelectual, no contexto da guerra, remetem, não sem perplexidade, à exigência de releitura constante de Descartes. Somos herdeiros de uma atitude de 
pensamento cuidadosa, metódica, que valoriza a organização de ideias, a estruturação de problemas em etapas e a revisão sem precipitação do que produzimos. Tudo isso aponta para uma imagem do sujeito do conhecimento dotada de estratégias para excluir procedimentos não planejados e comportamentos considerados inconsistentes. Séculos de erudição não impediram as catástrofes do século XX ou os extermínios recentes. Uma forte produção intelectual baseada na concepção cartesiana, voltada para a valorização do cuidado com as ideias e com as consequências das escolhas, não foi suficiente para esse impedimento. Pelo contrário, uma produção com essa fundamentação se tornou base sólida para instrumentalizar a destruição de milhões de seres humanos.

A concepção cartesiana de pensamento está relacionada a uma estética, a da narrativa realista. Ian Watt apresenta uma explicação exemplar, no livro A ascensão do romance. Em várias obras, em especial no século XIX europeu, é possível observar, acompanhando Watt, uma articulação entre forma e pensamento. A construção do romance realista tradicional europeu, em diversos casos, é apoiada em um narrador que se caracteriza pela imagem de objetividade. É como se para ele fosse plausível compreender tudo o que delimita a matéria narrada. Em Theodor Adorno, o problema do narrador se apresenta de modo diverso. A ideia de um realismo totalizante, para ele, é ilusória, como uma "mentira da representação" (ADORNO, 2003, p. 60). A partir de autores como Marcel Proust e Franz Kafka, o campo da narrativa se define de modo diferente do realismo tradicional. Há uma "permanente ameaça de catástrofe" (ADORNO, 2003, p. 61).

Articulando as reflexões de Ian Watt e Theodor Adorno, e inserindo em um contexto de história das ideias, podemos formular uma hipótese. As guerras do século XX estabeleceram um desafio para a Teoria da Literatura, assumido por Adorno, em seu ensaio "Posição do narrador no romance contemporâneo", de 1954. No romance realista do século XIX, pode ser observada a presença constante de um narrador com uma caracterização em que há ênfase em um estilo pautado por um senso de unidade, dando impressão de unidade e coerência. A partir do final do século XIX, e ao longo das primeiras décadas do século XX, ocorre uma transformação nos modos de narrar, em favor de uma desconstrução do modelo anterior. Ocorre um movimento que, a partir de um modelo de narração cartesiano (seguindo aqui rigorosamente Ian Watt, para a escolha do termo), se dirige para uma produção que contraria esse modelo. Quando Adorno escreve em 1954 sobre essa produção, observa que existem relações entre o problema da narrativa realista e o contexto histórico.

Adorno apresenta em seu ensaio a seguinte proposição: "se o romance quiser permanecer fiel à sua herança realista e dizer como realmente as coisas são, então ele precisa renunciar a um realismo que, na medida em que reproduz a fachada, apenas a auxilia na produção do engodo. [...] Por meio de choques ele [Kafka] destrói no leitor a tranquilidade contemplativa diante da coisa lida. Seus romances, se é que de fato eles ainda cabem nesse conceito, são a resposta antecipada a uma constituição do mundo na qual a atitude contemplativa tornou-se um sarcasmo sangrento, porque a permanente ameaça de catástrofe não permite mais a observação imparcial, e nem mesmo a imitação estética dessa situação" (ADORNO, 2003, p. 57-61). Seguindo esta premissa, seria o caso de estabelecer que a objetividade do narrador realista seria possível porque a ficção estaria pautada por perspectivas totalizantes. Historicamente, sabemos que havia guerras nos séculos XVIII e XIX e que romances realistas se referiram a elas. Cabe observar que, ao longo do século $\mathrm{XX}$, foram escritos romances com narradores que, de acordo 
com os parâmetros de Watt, são rigorosamente realistas, sendo possível destacar, por exemplo, as configurações de romances históricos.

O que importa a Adorno como prioridade, e que faz com que ele critique a atitude contemplativa, e sobretudo o realismo de fachada, é o comportamento marcado por empatia. Trata-se de estabelecer contato subjetivo com o sofrimento. No caso das guerras, uma empatia que indique comoção com o que há de humano na destruição. $\mathrm{O}$ ponto de vista estabelecido como objetivação, que procura dar impressão de distanciamento, e que tenta iludir com a imagem de isenção e neutralidade, se antes poderia parecer uma virtude formal, em Adorno passa a ser "sarcasmo sangrento", um olhar cínico diante do sofrimento humano. Cabe retomar Descartes mais uma vez. A ilusão de objetividade do procedimento cartesiano de construção de verdade organização de pensamento, controle das ideias precipitadas, revisão - é um sistema contra a vulnerabilidade humana. Mais precisamente, contra a imagem do humano como vulnerável. Trata-se de um método avesso à fragilidade, para contornar chances de erro. O horizonte de Adorno acentua, por sua vez, utilizando um vocabulário com termos como catástrofe e epopeia negativa, a vulnerabilidade constitutiva do sujeito.

Cinquenta e sete anos depois do ensaio de Adorno, o problema das relações entre guerra e literatura é da maior atualidade. Os extermínios não cessaram. Muitos processos de destruição em massa aconteceram após a publicação do ensaio adorniano: em espaços como a ditadura argentina, o massacre de Hamah, as matanças na Indonésia em 1965, o massacre de Dao County, as matanças de Burundi em 1972, os massacres em Sri Lanka em 1983, o ato repressivo em Burma em 1988, a deportação coletiva de habitantes da Xexênia, entre outros. Na África, os movimentos de transformação política em processos históricos referentes à condição pós-colonial foram decisivos para a sobrevivência em países lusófonos. Diante desse real constituído como trauma, os escritores comportam-se de diversos modos. Alguns conservam práticas estéticas oitocentistas, convictos de que o valor das narrativas lineares permanece. Outros caminhos são escolhidos - testemunhos, cartas, crônicas, diários, autobiografias. Alguns textos são construídos de tal modo que nenhuma das categorias conhecidas de classificação de gêneros literários parece suficiente para descrever sua fisionomia.

Em 1936, Walter Benjamin escreveu que a arte de narrar estava em declínio. O horizonte histórico em que dizia isso exigia a necessidade de encarar o impacto da guerra. Ele acreditava que soldados voltavam da guerra pobres de experiências para contar (BENJAMIN, 1985). Em seu ensaio convergiam o trauma da guerra e a inviabilidade da narração. No mesmo texto sobre o narrador, Benjamin dedica atenção ao modo de se encarar a morte, nos tempos que atravessava. No passado, segundo sua reflexão, a morte era considerada um componente da vida pública, envolvendo a comunidade. Benjamin observa a tendência moderna a afastar os mais velhos do convívio social. Se antes o mais velho era considerado aquele que acumulava mais experiências e tinha um papel extraordinário para a comunidade, ele passa a ser colocado à margem no campo da ordem produtiva. Os dois tópicos incluídos no ensaio de Benjamin são intimamente relacionados. O efeito danoso da guerra está para ele ligado à mudança histórica no modo de encarar a morte do outro. Ambos os assuntos são incluídos na reflexão por apontarem para uma insuficiência no valor atribuído à vida humana singular.

De acordo com essa orientação, as reflexões da Literatura Comparada e da Teoria da Literatura estariam necessariamente vinculadas ao estudo de Ética. As configurações referentes aos modos de narrar exigem considerações sobre a História, 
permanências, mudanças, e envolvem posições, juízos. Quando o assunto estudado, direta ou indiretamente, envolve guerra, conflitos, diferença, as relações entre tema e forma devem ser cuidadosamente observadas. Para resgatar o valor singular da vida humana na atualidade, um escritor como Sergio Chejfec, em um ótimo livro como Lenta biografia, coloca em suspensão as categorias habituais de gêneros textuais. As inclinações a falar em romance, autobiografia e testemunho não são suficientes. Trata-se de um livro perturbador: a Segunda Guerra Mundial está ali presente, a repressão latinoamericana em sua violência próxima também, e há nele ainda mais. O livro põe em dúvida o papel da palavra, do referente, a sustentação do narrar, o limite do literário. E faz isso em sintonia com o processo fantasmagórico de colocar em questão o limite entre vida e morte, incontornável diante da escala histórica em que se insere. Não é o livro Lenta biografia que precisa se ajustar às categorias classificatórias. A partir da preciosa contribuição de Chejfec, é a Teoria da Literatura que precisa se articular para compreender esse fenômeno delicado do encontro entre literatura e guerra.

$\mathrm{Na}$ tradição antiga e medieval, imagens da guerra eram inseridas em formas épicas. O gênero épico era caracterizado pela afirmação positiva do herói, em sua capacidade de enfrentamento de inimigos e realização de conquistas. Essa tradição não está destituída de heranças, que surgem inclusive na indústria cultural. A configuração épica aponta para uma necessidade de guerra, que se justificaria por consolidação de soberania social, estabelecimento de fronteiras, ou ainda por sobrevivência frente a um risco de dominação. Um caso exemplar de elogio da guerra é o poema De gestis, redigido por José de Anchieta no século XVI. Em homenagem a Mem de Sá, comparado no texto a Jesus Cristo, o poema propõe que, sendo indígenas seres dominados pelo demônio, sua destruição purifica a terra. A legitimidade da guerra, nesse caso, é religiosa e política. A estrutura do texto é pautada pela Eneida de Virgílio. Completamente diverso do registro épico é o caso do Diário alemão de Guimarães Rosa. O documento se refere ao período em que esteve em Hamburgo, durante o nazismo. Nele não há nada virtuoso nos atos guerreiros. Pelo contrário, ali prevalece o senso de que estar dentro do conflito é uma exposição ao sofrimento constante, um estado-limite, em que a capacidade de entendimento da realidade é posta em questão.

A incidência de bombas junto ao Consulado Brasileiro em que Rosa trabalhava e à sua residência configuram um cenário de risco de vida, em meio a uma Hamburgo ameaçada por bombardeios. As referências constantes a alarmes caracterizam uma situação de tensão continuada. O heroísmo antigo articula imagens sublimes, de harmonia e elevação. $\mathrm{O}$ impacto do estado limite traz a cadaverização, o abjeto e a fragmentação de um mundo em ruína. Entre a altissonância épica e a fragmentação do Diário de Rosa, existe uma ampla variedade de configurações literárias da guerra. Chama a atenção, entre os textos que a elogiam, o trabalho de José de Alencar, Cartas a

favor da escravidão, em que o nacionalista romântico brasileiro se dedica a criticar a noção de paz:

\section{SEXTA CARTA}

Sobre a guerra

Senhor

A paz é uma grande vergonha...

O coração brasileiro se congela ao som desta palavra cruel. Reflui o sangue açoitando as faces do cidadão brioso, que se estremece pela honra nacional. A paz é um ato de miséria... 
O Brasil, a segunda nação da América, destinado à primazia do mundo, abater seu estandarte ante o arreganho de um pequeno déspota, quase selvagem?

Não há filho deste império que se não possua de horror ante a possibilidade de semelhante opróbrio.

A paz é uma vilania... (ALENCAR, 2008, p. 133).

$\mathrm{Na}$ medida em que as reflexões em Estética forem articuladas com Ética e Política, o problema do respeito à alteridade se apresenta como parte importante do debate. O texto de José de Alencar aponta para um problema importante: em um mundo em que soberania política é uma prioridade, o prestígio da guerra não é pouco. $\mathrm{O}$ pacifismo, por sua vez, anda em descrédito. O conceito de paz dominante hoje é operacional e estritamente estratégico: trata-se de um controle de potenciais de conflitos, em acordo com interesses de nações economicamente hegemônicas. A paz, como generalização, é constantemente observada como utopia associada às ideias que teriam se cristalizado nos anos 60. Os processos históricos contemporâneos evidenciaram com clareza que os esforços destrutivos são muito mais intensos e ágeis do que os movimentos pacifistas. Isso está ligado ao fato de que o problema levantado por Adorno e Horkheimer, referente à razão instrumental, permanece inteiramente atual. É perfeitamente possível manter o rigor cartesiano para realizar sistematicamente o ato de matar. É nesse contexto que se tornam prioritários debates em Teoria da Literatura e Literatura Comparada sobre os modos de pensar imagens da guerra, levando em conta a tradição épica e os conflitos sociais da atualidade. Textos como o Diário de Guimarães Rosa e Lenta Biografía de Chejfec resistem à classificação e descrição pelos critérios convencionais disponíveis. Um pensamento sobre literatura capaz de explicar o que propõem esses textos é também um pensamento crítico capaz de confrontar o impacto da guerra de frente.

\section{BIBLIOGRAFIA}

ADORNO, Theodor. Posição do narrador no romance contemporâneo. In: . Notas de literatura I. São Paulo: Editora 34, 2003. e HORKHEIMER, Max. Dialética do esclarecimento. Rio de Janeiro: Zahar, 1985.

ALENCAR, José de. Cartas a favor da escravidão. São Paulo: Hedra, 2008.

ANCHIETA, José de. De gestis Mendi de Saa poema epicum. São Paulo: MEC, 1970. BENJAMIN, Walter. O narrador. In: . Magia e técnica, arte e política. São Paulo, Brasiliense, 1985.

CELAN, Paul. Cristal. São Paulo: Iluminuras, 1999.

CHEJFEC, Sergio. Lenta biografia. Buenos Aires: Aguilar, 2007.

DESCARTES, René. Discurso do método. In: Discurso do método. Meditações. Objeções e respostas. As paixões da alma. Cartas. São Paulo: Abril Cultural, 1973. HABERMAS, Jurgen. Conhecimento e interesse. In: Et all. Textos escolhidos. São Paulo: Abril Cultural, 1983.

HARDMAN, Francisco Foot. O sol destronado. Estado de São Paulo. 21.03.2011. p. 7. 
ROSENFELD, Anatol. Arte e fascismo. In: Texto / contexto II. São Paulo: Perspectiva, 1993.

SOUZA, Eneida Maria, OTTE, Georg e MARQUES, Reinaldo (organização). Diário de guerra de João Guimarães Rosa. Documento do Acervo de Escritores Mineiros da UFMG. Inédito [consultado com autorização dos organizadores].

WATT, Ian. A ascensão do romance. São Paulo: Companhia das Letras, 1990.

WEIL, Simone. A Ilíada ou o poema da força. In: A condição operária e outros estudos sobre a opressão. Rio de Janeiro: Paz e Terra, 1979.

WITTGENSTEIN. Investigações filosóficas. São Paulo: Abril Cultural, 1975. 